\title{
Comparison and Application of Two types of Filling Gel to Prevent Spontaneous Combustion at the Region where Top-Coal Caves above Entry
}

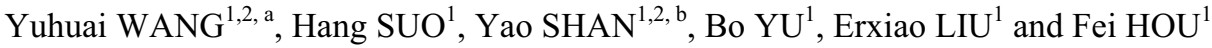 \\ ${ }^{1}$ North China Institute of Science and Technology, Beijing, 101601, China \\ ${ }^{2}$ Hebei Province Key Laboratory of Mine Disaster Prevention, Beijing, 101601, China \\ a785281919@qq.com, b9106350@qq.com
}

\begin{abstract}
Two types of gel were developed, by taking fly ash and foaming cement as aggregate, which is usually used as filling material at the region where top-coal caves above coal entry in the Jinggezhuang coal mine, and adding high molecular polymer and bio-gel as additive. Sweating rates of the two types of gel under various matching ratio and temperature were tested. And then sweating ratio and water retention ratio of the two gels were calculated, based on which, the optimized matching ratios, were determined. Viscosity indexes of the two-type gel under different ratios were tested. The optimized filling ratios of the two types of gel were determined according to the two indexes, water retention rate and the viscosity. The filling experiments were implemented and evaluated in site, the Jinggezhuang coal mine. The results show that the fly ash gel has a good achievement on preventing spontaneous combustion at the Region where Top-Coal Caves above entries. It is promising, economically and environmental friendly, and valuable in popularization in coal mines.
\end{abstract}

Keywords: top-coal caving region; gel; sweating rate; water retention rate; viscosity

\section{Introduction}

The Jinggezhuang coal mine is mining out, and start to excavate the bound coal and pillar in recent years. The main working face is located at $9 \#$ coal seam, which is classified as a prone to spontaneous combusting seam, average $7.5 \mathrm{~m}$ thick in thickness. Because of a lot of faults, old chambers and gob areas in the coal seam, the top-coal broke and fell during development and many cavities formed. Therefore, potential hazard of spontaneous combustion in the entries during retreat mining emerged. In order to prevent the potential hazard in the coal seam, method of filling with fly ash and foamed cement were applied in the top-coal caving region of the entries in the Jinggezhuang coal mine. The problems were those: 1) the result of filling is not acceptable satisfied, and 2) cost is high. Therefore, it is necessary to develop a 
new filling material to prevent the spontaneous combustion in the top-coal caving region, with good filling achievement and low cost.

\section{Selection of the Gel}

The technologies currently used for prevention coal spontaneous combustion include water injection, grouting, plugging, inerting, gel injection, etc [1]. The filling-gel technology to extinguish fire is one of the most important techniques to prevent coal spontaneous combustion [2-3]. The gel suitable for coal mine using should coincide with the following requirements: non-poisonous, harmless, no peculiar smell, no pollution, good in permeability and high temperature resistance to prevent the material from gasifying rapidly, good in heat absorption performance so as to cool the coal rapidly, good in the abilities of plugging, and inhibiting coal oxidation, convenient to construct, and low in cost [3-5].

\section{Selection of the Aggregates}

A popular additive material for making gel is polyacrylamide (PAM). The PAM is a strong flocculate, good in adhesion and thickening [6]. The function of flocculation can make the suspending material bridging adsorpted through electric neutralization [7].

It was found, in the experiments, that the water solution of PAM was close to a transparent viscous liquid, and the viscosity is low. For this reason, settlement happened after mixing with the fly ash or foaming cement so uniform gel can't form. The experiment shows that the mixture of bio-gel (PX) and PAM at a certain mixing ratio can increase the viscosity, and enhance the stability of gel. Therefore, the PX and PAM were selected as the additive materials of the gels.

\section{Testing of the Properties of the Gels}

The Sweating Rate, Sweating Ratio and Water Retention Ratio

For each group of experiments, the aggregate weight was $90 \mathrm{~g}$, and the water $150 \mathrm{ml}$, based on previous investigation experiments. The PAM and PX were added at various ratio and then mixed with the aggregate and water together. The sweating rates of the two gels were tested at temperature $20^{\circ} \mathrm{C}, 30^{\circ} \mathrm{C}, 50^{\circ} \mathrm{C}, 70^{\circ} \mathrm{C}$, etc. The gels were kept in a thermostat at constant temperature for a certain time. Then they were taken out for testing and analyzing the changes of sweating rate in different condition. The sweating ratio were obtained through dividing the quantity of extracted water by the total quantity of water in the get. The water retention ratio of gel can be obtained through the sweating ratio of gel, as shown in:

$$
\beta=100 \%-\alpha
$$

Where: $\beta$ is water retention ratio, and $\alpha$ is sweating ratio.

Testing and Analyzing of Sweating Rate and Sweating Ratio of the Fly Ash Gel Testing Data

16 groups of experiments, in which the fly ash was used as the aggregate material, in various temperatures and mixing ratios, were carry out, to test the sweating rate and ratio. Four distinct groups of which are shown in the Fig.1 to Fig.4. 


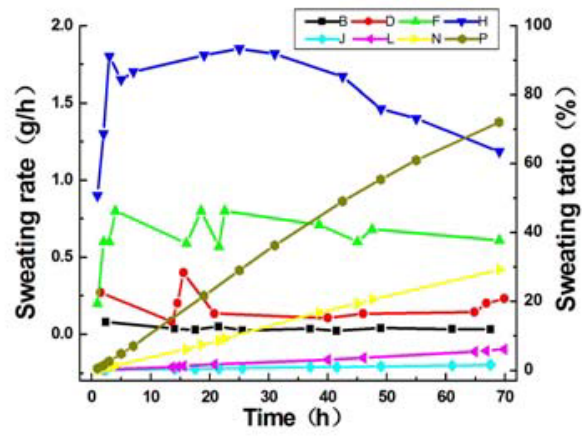

Fig.1 The sweating rate and sweating ratio of the fly ash gel at various temperature at a constant PX and PAM ratio of $0.75 \%$ and $0.5 \%$, respectively

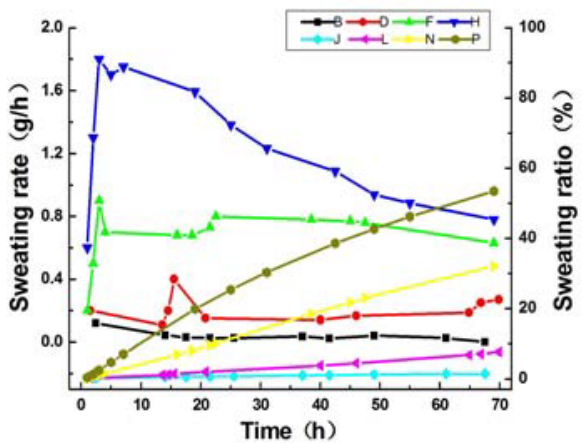

Fig.2 The sweating rate and sweating ratio of the fly ash gel at various temperature at a constant PX and PAM ratio of $0.875 \%$ and $0.75 \%$, respectively

(Where $\mathrm{B}$ is sweating rate at $20^{\circ} \mathrm{C}, \mathrm{D}$ is sweating rate at $30^{\circ} \mathrm{C}, \mathrm{F}$ is sweating rate at $50^{\circ} \mathrm{C}, \mathrm{H}$ is sweating rate at $70^{\circ} \mathrm{C}, \mathrm{J}$ is sweating ratio at $20^{\circ} \mathrm{C}, \mathrm{L}$ is sweating ratio at $30^{\circ} \mathrm{C}, \mathrm{N}$ is sweating ratio at $50^{\circ} \mathrm{C}, \mathrm{P}$ is sweating ratio at $70^{\circ} \mathrm{C}$, same pattern is used in the following figures)

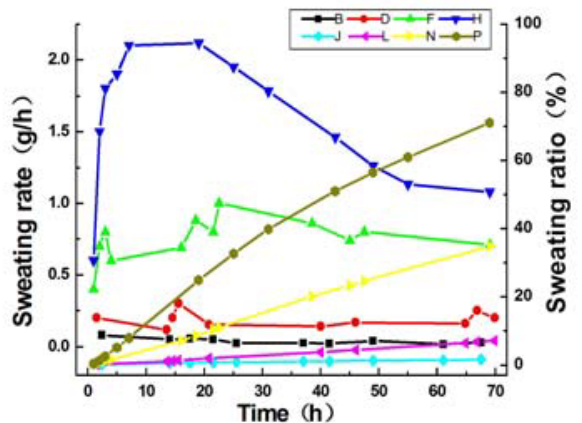

Fig.3 The sweating rate and sweating ratio of the fly ash gel at various temperature at a constant PX and PAM ratio of $1 \%$ and $0.625 \%$, respectively

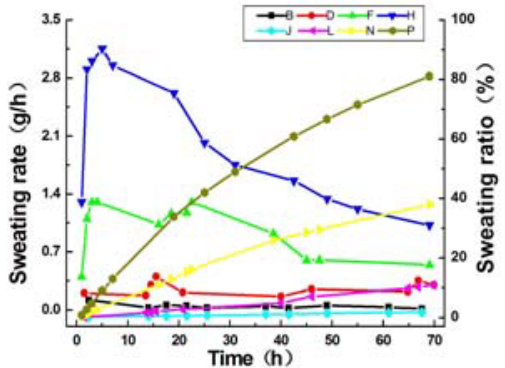

Fig.4 The sweating rate and sweating ratio of the fly ash gel at various temperature at a constant PX and PAM ratio of $1.125 \%$ and $0.375 \%$, respectively

\subsection{Analysis of the Testing Result}

As showing in the Fig.1 to Fig.4, the sweating rate of fly ash gel exhibited various change trend with time under different temperature. And the sweating ratio increased gradually with time. The sweating rate at temperature $20^{\circ} \mathrm{C}$ and $30^{\circ} \mathrm{C}$ changed slightly with time, and the corresponding ratio after 72 hours were no more than $5 \%$ and $10 \%$, respectively. The sweating rate at $50^{\circ} \mathrm{C}$ increased in an increase-decrease-increase-decrease mode. The change of sweating rate under $70^{\circ} \mathrm{C}$ was the most distinct, increased at first then decreased.

Observing the change trend at temperature $50{ }^{\circ} \mathrm{C}$ in particular: the sweating rate reached top at $0.9 \mathrm{~g} / \mathrm{h}$, the sweating ratio was $32.9 \%$ after $72 \mathrm{~h}$, if the mixing ratio was: the PX $0.75 \%$ 
and the PAM $0.5 \%$; the sweating rate reached top at $0.8 \mathrm{~g} / \mathrm{h}$, the sweating ratio was $32.0 \%$ after $72 \mathrm{~h}$, if the mixing ratio was: the PX $0.875 \%$ and the PAM $0.75 \%$; the sweating rate reached top at $1.0 \mathrm{~g} / \mathrm{h}$, the sweating ratio was $34.8 \%$ after $72 \mathrm{~h}$, if the mixing ratio was: the PX $1 \%$ and the PAM $0.625 \%$; the sweating rate reached top at $1.3 \mathrm{~g} / \mathrm{h}$, the sweating ratio was $37.9 \%$ after $72 \mathrm{~h}$, if the mixing ratio was: the PX $1.125 \%$ and the PAM $0.375 \%$.

At temperature $70{ }^{\circ} \mathrm{C}$ : the sweating rate reached top at $1.9 \mathrm{~g} / \mathrm{h}$, the sweating ratio was $72.0 \%$ after $72 \mathrm{~h}$, if the mixing ratio was: the PX $0.75 \%$ and the PAM $0.5 \%$; the sweating rate reached top at $1.8 \mathrm{~g} / \mathrm{h}$, the sweating ratio was $53.4 \%$ after $72 \mathrm{~h}$, if the mixing ratio was: the PX $0.875 \%$ and the PAM $0.75 \%$; the sweating rate reached top at $2.1 \mathrm{~g} / \mathrm{h}$, the sweating ratio was $71.0 \%$ after $72 \mathrm{~h}$, if the mixing ratio was: the PX $1 \%$ and the PAM $0.625 \%$; the sweating rate reached top at $3.1 \mathrm{~g} / \mathrm{h}$, the sweating ratio was $81.0 \%$ after $72 \mathrm{~h}$, if the mixing ratio was: the PX $1.125 \%$ and the PAM $0.375 \%$.

The test results showed that, keeping the sample of fly ash gel at temperature $70^{\circ} \mathrm{C}$ for 72 hours, the water retention rate was basically around $30 \%$, the highest value was $46.6 \%$. At temperature $50^{\circ} \mathrm{C}$, and incubated for 72 hours the water retention rate was basically around $65 \%$, the highest values was $68.0 \%$. At temperature $30^{\circ} \mathrm{C}$, the water retention rate and the highest value were more than $90 \%$, and $95 \%$, respectively. At temperature $20^{\circ} \mathrm{C}$, they were more than $95 \%$, and $98.5 \%$, respectively. It is suggested that, the optimized mixing ratio was the PX at $0.875 \%$ and the PAM at $0.75 \%$, in which the sweating ratio of fly ash gel as the lowest and the water retention ratio was the highest.

Testing and Analysis of the Sweating Rate and Ratio of the Foamed Cement Gel

Data of the Test

16 groups of experiments, in which the foamed cement was used as the aggregate material, in various temperatures and mixing ratios, were carry out, to test the sweating rate and ratio. Four distinct groups of which are shown in the Fig.5 to Fig.8.

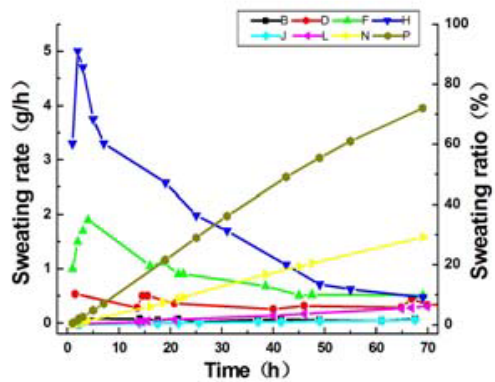

Fig.5 The sweating rate and sweating ratio of the foamed cement gel at various temperature at a constant PX and PAM ratio of $0.75 \%$ and $0.5 \%$, respectively

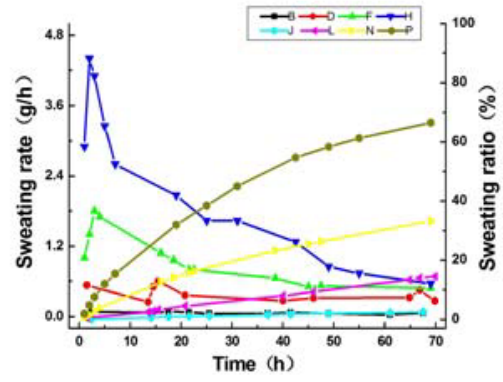

Fig.6 The sweating rate and sweating ratio of the foamed cement gel at various temperature at a constant PX and PAM ratio of $0.875 \%$ and $0.75 \%$, respectively 


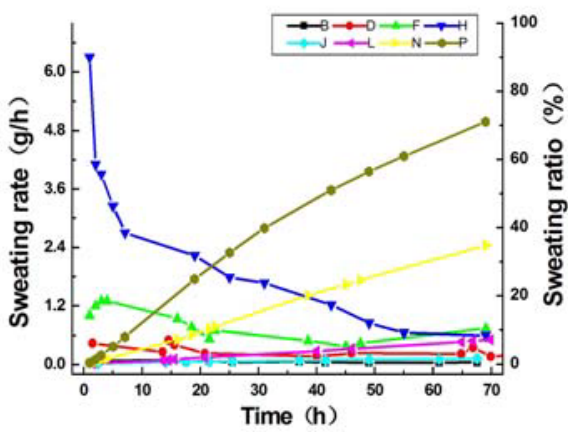

Fig.7 The sweating rate and sweating ratio of the foamed cement gel at various temperature at a constant PX and PAM ratio of $1 \%$ and $0.625 \%$, respectively

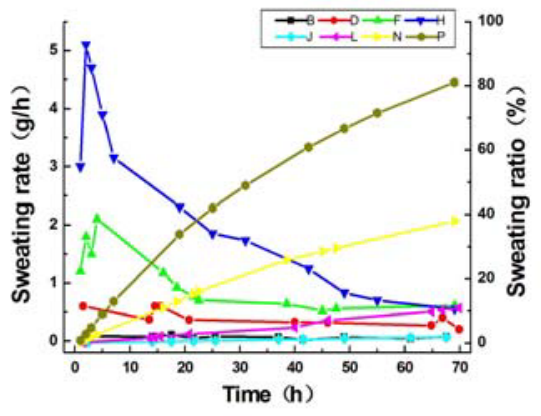

Fig.8 The sweating rate and sweating ratio of the foamed cement gel at various temperature at a constant PX and PAM ratio of $1.125 \%$ and $0.375 \%$, respectively

\subsection{The Analysis of Test Results}

As showing in the Fig.1 to Fig.4, the sweating rate of the foamed cement gel showed an increase-decrease trend. And the sweating ratio increased fast with time at first and then slowed down. The sweating rate at temperature $20^{\circ} \mathrm{C}$ and $30^{\circ} \mathrm{C}$ changed slightly with time, and the corresponding ratio after 72 hours were no more than $5 \%$ and $15 \%$, respectively. The sweating rate at $50^{\circ} \mathrm{C}$ and $70^{\circ} \mathrm{C}$ were distinct and showed the trend that increase at first then decrease.

Observing the change trend at temperature $50^{\circ} \mathrm{C}$ in particular: the sweating rate reached top at $1.9 \mathrm{~g} / \mathrm{h}$, the sweating ratio was $34.3 \%$ after $72 \mathrm{~h}$, if the mixing ratio was: the PX $0.75 \%$ and the PAM $0.5 \%$; the sweating rate reached top at $1.8 \mathrm{~g} / \mathrm{h}$, the sweating ratio was $33.2 \%$ after $72 \mathrm{~h}$, if the mixing ratio was: the PX $0.875 \%$ and the PAM $0.75 \%$; the sweating rate reached top at $1.3 \mathrm{~g} / \mathrm{h}$, the sweating ratio was $33.2 \%$ after $72 \mathrm{~h}$, if the mixing ratio was: the PX $1 \%$ and the PAM $0.625 \%$; the sweating rate reached top at $2.1 \mathrm{~g} / \mathrm{h}$, the sweating ratio was $31.6 \%$ after $72 \mathrm{~h}$, if the mixing ratio was: the PX $1.125 \%$ and the PAM $0.375 \%$.

At temperature $70^{\circ} \mathrm{C}$ : the sweating rate reached top at $4.7 \mathrm{~g} / \mathrm{h}$, the sweating ratio was $71.5 \%$ after $72 \mathrm{~h}$, if the mixing ratio was: the PX $0.75 \%$ and the PAM $0.5 \%$; the sweating rate reached top at $4.5 \mathrm{~g} / \mathrm{h}$, the sweating ratio was $66.5 \%$ after $72 \mathrm{~h}$, if the mixing ratio was: the PX $0.875 \%$ and the PAM $0.75 \%$; the sweating rate reached top at $6.3 \mathrm{~g} / \mathrm{h}$, the sweating ratio was $70.2 \%$ after $72 \mathrm{~h}$, if the mixing ratio was: the PX $1 \%$ and the PAM $0.625 \%$; the sweating rate reached top at $5.1 \mathrm{~g} / \mathrm{h}$, the sweating ratio was $71.7 \%$ after $72 \mathrm{~h}$, if the mixing ratio was: the PX $1.125 \%$ and the PAM $0.375 \%$.

The test results show that, keeping the sample of foamed cement gel at temperature $70^{\circ} \mathrm{C}$ for 72 hours, the water retention rate is basically around $30 \%$, the highest value was $35.5 \%$. At temperature $50{ }^{\circ} \mathrm{C}$, and incubatied for 72 hours the water retention rate is basically around $60 \%$, the highest values is $69.60 \%$. At temperature $30^{\circ} \mathrm{C}$, the corresponding water retention rate and the highest values were more than $85 \%$ and $87 \%$, respectively. At temperature of $20^{\circ} \mathrm{C}$, the corresponding water retention rate and the highest values were more than $95 \%$ and $97.8 \%$, respectively.

Comparing with the fly ash gel, the foamed cement gel has a higher sweating rate at first, then decreased with time. On the other hand, the water retention rate of the foamed cement gel at different ratio showed different regularity. After comprehensive comparison, the optimal mixing patter with the best water retention ratio was determined in descending order 
as following: (1PX0.875\%, PAM0.75\%; (2)PX0.75\%, PAM0.5\%; (3PX1\%, PAM0.625\%; (4) PX $1.125 \%, \mathrm{PAM} 0.375 \%$.

\section{Determining the Optimum Filling Ratios of the Gel Materials}

According to laboratory tests, the appropriate viscosity of gel material for filling was $25 \sim 30 \mathrm{pa} \cdot \mathrm{s}$. In this range the gel material has good fluidity, and could flow adequately in the broken coal of top-coal caving region and cover the broken coal, at the same time it won't lead to large amount gel flowing out or blocking the equipment.

The viscosity of the two gels with different ratios was tested. The test results are shown in Table 1 and Table 2.

TABLE 1 VISCOSITY OF FLY ASH GEL AT DIFFERENT RATIOS

\begin{tabular}{|c|c|c|c|c|c|}
\hline & PX/\% & PAM/\% & Fly ash $/ \mathrm{g}$ & $\begin{array}{c}\text { Water } \\
/ \mathrm{g}\end{array}$ & Viscosity/pa·s \\
\hline Test 1 & 0.75 & 0.5 & 90 & 150 & 14 \\
\hline Test 2 & 0.875 & 0.75 & 90 & 150 & 28 \\
\hline Test 3 & 1 & 0.625 & 90 & 150 & 26 \\
\hline Test 4 & 1.125 & 0.375 & 90 & 150 & 21 \\
\hline
\end{tabular}

TABLE 2 VISCOSITY OF FOAMED CEMENT GEL AT DIFFERENT RATIOS

\begin{tabular}{|c|c|c|c|c|c|}
\hline & $\mathrm{PX} / \%$ & $\mathrm{PAM} / \%$ & $\begin{array}{c}\text { Foamed } \\
\text { cement } / \mathrm{g}\end{array}$ & $\begin{array}{c}\text { Water } \\
/ \mathrm{g}\end{array}$ & $\begin{array}{c}\text { Viscosity/pa } \\
\cdot \mathrm{s}\end{array}$ \\
\hline Test 1 & 0.75 & 0.5 & 90 & 150 & 21 \\
\hline Test 2 & 0.875 & 0.75 & 90 & 150 & 20 \\
\hline Test 3 & 1 & 0.625 & 90 & 150 & 24 \\
\hline Test 4 & 1.125 & 0.375 & 90 & 150 & 36 \\
\hline
\end{tabular}

Fortunately, fly ash gel with the best water retention ratio coinciding with the requirement, and the best filling ratio is $0.875 \%$ of $\mathrm{PX}$ and $0.75 \%$ of $\mathrm{PAM}$, which has a viscosity of $28 \mathrm{pa} \cdot \mathrm{s}$.

\section{Structure Analysis of the Gels}

The samples of two types of gels were analyzed by SEM. Particles of foamed cement gel are finer and the gap is less than the fly ash gel. Pore of the fly ash gel is very clear, which can be very effective to confine water and reduce sweating of water. The crystal structure of the fly ash doesn't change. The fly ash not only absorbs water by capillary pore between particles, but also stores water in cave of broken particles and honeycomb porosity. So the ability of water retention of fly ash gel is better than the foamed cement gel.

\section{The Application of Filling Gel in Site}

The pilot experiments of filling two types of gel were implemented at top-coal caving region of the coal entry in the Jinggezhuang coal mine. A $50 \mathrm{~kg}$ fly ash gel was injected by pneumatic-pump into the bore located at $36 \mathrm{~m}$ in the intake entry of 0090 work face of the No.9 coal seam. Another $50 \mathrm{~kg}$ foamed cement gel was injected into a bore located at $73 \mathrm{~m}$ in the same entry. The temperature in the filled entry was tested after injection, showing in the table 3. The fly ash gel is better than the foamed cement gel in the aspect of filling and 
cooling according to the temperature tested in the entry. The fly ash gel could fill the top-coal caving region and cool the surrounding coal effectively at the same time. Therefore, it can prevent the spontaneous combustion in the top-coal caving region effectively.

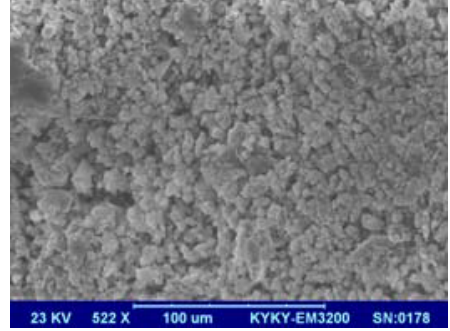

Fig.9 SEM image of foamed cement gel amplified 500 times

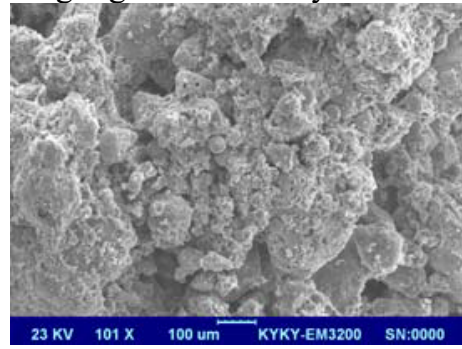

Fig.10 SEM image of fly ash gel amplified 100 times

TABLE 3 TEMPERATURE OF FILLED DRILL HOLES IN INTAKE ENTRY OF 0090 WORK FACE

\begin{tabular}{|c|c|c|}
\hline observation date & $\begin{array}{c}\text { The fly ash gel injected into the } \\
\text { bore located at } 36 \mathrm{~m}\end{array}$ & $\begin{array}{c}\text { the foamed cement gel into the } \\
\text { bore located at } 73 \mathrm{~m}\end{array}$ \\
\hline 10.17 & 24 & 27 \\
\hline 10.18 & 21 & 29 \\
\hline 10.19 & 21 & 28 \\
\hline 10.24 & 22 & 28 \\
\hline 10.31 & 24 & 27 \\
\hline 11.01 & 24 & 29 \\
\hline
\end{tabular}

\section{Conclusion}

By studying the sweating rate, water retention and viscosity of the two types of gel, the best ratios of the two types of gel were obtained. The field filling test showed that the fly ash gel material has the advantage of low sweating rate, good water retention and appropriate viscosity, suitable for application in shaft coal mines as they are easy and fast to inject and can cool the the surrounding coal to prevent spontaneous combustion in the top-coal caving region effectively. It is promising, economically and environmental friendly, and valuable in popularization in coal mines.

\section{Acknowledgement}

This article is supported by the followings: National Natural Science Foundation of China (U1361130), the Fundamental Research Funds for the Central Universities (3142015021, 3142015071).

\section{References}

1. J. Deng, N. Wang, H. Wen, et al, Study on fire protection characters of high-water Gel, Safety in Coal Mines. 42-7(2011) 32-35.

2. Q. Li, X. Zhang, X. Fan, et al, Application of composite fly ash gel to extinguish fire in Dongrong No.3 coal mine, China Safety Science Journal. 15-4 (2013) 45-47.

3. J. Xu, X. Zhang, H. Wen, et al, Theory and technology of gel fire protection spontaneous combustion in coal seam., Coal Industry Press, 2003. 
4. J. Ji, C. Wang, W. Lu, et al., Research on fire protection gel material JTJ in coal mine, Mining Safety and Environmental Protection. 35-2(2008) 19-21.

5. Y. Chen, Spontaneous combustion prevention of coal drift with high caved point based on MEA gel material, Safety in Coal Mines. 46-2(2015) 125-127.

6. Y. Zou, P. He, Y. Zhang, et al, Research progress of heat resistance and salt tolerance PAM, Gel and Polymer. 29-3(2011) 138-140.

7. B. Yao, Y. Zhang, H. Yang, Study status on stabilizer of coal water slurry, Coal Science and Technology. 41-11(2013) 124-128. 